\title{
Alkali-Metal-Directed Hydrolytic Condensation of 3-Mercaptopropyltrimethoxysilane
}

\author{
Maria Nowacka • Anna Kowalewska • \\ Krystyna Gadzinowska
}

Received: 8 May 2014 / Accepted: 15 September 2014 / Published online: 11 December 2014

(C) Springer Science+Business Media Dordrecht 2014

\begin{abstract}
A series of solid sodium and potassium cyclotetrasiloxanolates was synthetized with high yields by hydrolytic condensation of 3-mercaptopropyltrimethoxysilane in the presence of potassium or sodium hydroxide. The obtained materials were characterized using solid state ${ }^{29} \mathrm{Si}$ and ${ }^{13} \mathrm{C}$ NMR, wide angle X-ray scattering (WAXS), elemental analysis, Fourier transform infrared spectroscopy (FTIR), thermogravimetric analysis (TGA) and differential scanning calorimetry (DSC). The influence of reaction conditions on the structure and physiochemical properties of the obtained products was studied.
\end{abstract}

Keywords Cyclosiloxanolate $\cdot$ Hydrolytic condensation · 3-mercaptopropyltrialkoxysilane

\section{Introduction}

Linear ladder-like polysilsesquioxanes (LPSQs) are polymeric inorganic-organic hybrid materials consisting of a double stranded siloxane backbone with organic functional groups pendant on both sides. Due to their interesting physiochemical properties [1] LPSQs have been attracting a growing interest since their synthesis was announced for the first time by Brown et al. in 1960 [2]. Exhibiting many excellent properties, such as outstanding thermooxidative and photochemical stability, low flammability, excellent dielectric properties and mechanical stability, ladder-like polysilsesquioxanes can be applied as protective

M. Nowacka $(\bowtie) \cdot$ A. Kowalewska $\cdot$ K. Gadzinowska Centre of Molecular and Macromolecular Studies, Polish Academy of Sciences, Sienkiewicza 112, 90-363 Lodz, Poland e-mail: mnowacka@cbmm.lodz.pl coatings, insulating layers, aerospace materials and precursors of ceramics, photoresists etc. [1,3]. In addition, LPSQs (even those of high molecular weight) are well soluble in organic solvents. Chemical modification of organic side chain groups allows for the introduction of a variety of new functionalities. Physiochemical properties of LPSQs depend on the regularity of the structure of the polysiloxane framework.

Several synthetic methods were proposed for the preparation of ladder-like polysilsesquioxanes, including step wise coupling polymerization [3-7] or hydrolytic condensation of trifunctional organosilanes [2, 8-10]. However, the most promising method for the preparation of defect-free LPSQs is hydrolytic condensation of monomers containing cyclic siloxane units [11-19]. The most popular method for preparation of cyclic siloxane monomers is hydrolytic condensation of trialkoxyorganosilanes (Scheme 1) in the presence of water and an alkali metal hydroxide. It was found that properties of metal cations can influence the structure of the formed moieties since they work as template centers and structural elements helping to bind siloxane bonds into cyclic organosiloxanolate fragments [20-32]. While transition or rare-earth metal cations lead to the formation of varied-size $(n=4$ [20], 5 [21], 6, 8, 12 [22-24]) cyclic species, sodium and potassium cations enable the synthesis of small cyclosiloxanes containing three [25-28] or four [29-31] silicon atoms. Reaction parameters (the amount of water, type of organosilane and solvent) also can affect the ring size of cyclic products [32].

The syntheses of cyclotetrasiloxanolates functionalized at the Si atom with simple alkyl [34-37] and aryl [30, $33,34]$ groups have been reported. We wanted to prepare cyclotetrasiloxanolate precursors suitable for the synthesis of regular LPSQs, bearing side substituents capable of nucleophilic substitution or other chemical modifica- 


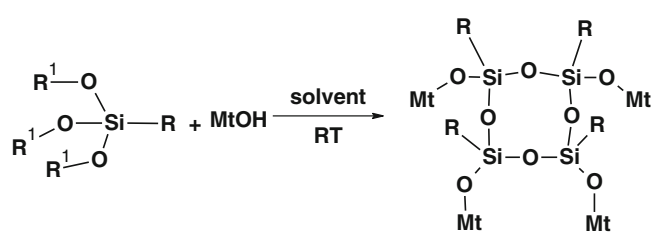

Scheme 1 Synthesis of cyclotetrasiloxanolates. $\mathrm{R}^{1}-\mathrm{Me}, \mathrm{Et}$; Mt metal, L - $\mathrm{H}_{2} \mathrm{O}$, EtOH; R - Ph [28, 33], $\mathrm{C}_{6} \mathrm{H}_{5}-\mathrm{OMe}$ [33], Np [33], NpOMe [33], $\mathrm{C}_{6} \mathrm{H}_{5} \mathrm{Br}[33,34]$, iBu [33, 34, 36], Me [37], Vi [37], Et [37], iPr [37]

tions. The presence of thiol groups in side chains would enable their functionalization by thiol-ene and thiol-yne addition, and thereby preparation of LPSQs with a large variety of functional groups. We have therefore studied the influence of reaction conditions (solvent; metal hydroxide $(\mathrm{MtOH}): \mathrm{Mt}=\mathrm{Na}, \mathrm{K} ;[\mathrm{MtOH}] /[$ silane]; [silane $] /\left[\mathrm{H}_{2} \mathrm{O}\right]$ ) on the structure and properties of cyclotetrasiloxanolates bearing 3-mercaptopropyl groups at silicon atoms.

\section{Results and Discussion}

Transformation of 3-mercaptopropyltrimetoxysilane into cyclic products was performed in the presence of water and potassium or sodium hydroxide. Two synthetic procedures were applied to study the effect of solvent and the amount of water on the structure of siloxanolate (Table 1, experimental details in the Supporting Information).

The first synthetic method was based on the procedure described by Ito et al. [33], originally for the preparation of cyclosiloxanolates with phenyl groups at the silicon atom. The reaction was carried out in ethanol using 3mercaptopropyltrimethoxysilane as the siloxane precursor and sodium or potassium hydroxide as an alkali metal source. The second procedure was described by Pozdnyakova et al. [34] for the synthesis of potassium cyclosiloxanolates with vinyl groups. The reaction was performed in a mixture of hexane and ethanol as a reaction medium, using potassium hydroxide as $\mathrm{MtOH}$.

We have chosen the above methods to compare the influence of the reaction conditions that originally were designed for two significantly different functional groups: small vinyl moieties, and phenyl groups that facilitate formation of regular cyclic products due to their rigid structure and size. Both methods led to the formation of solid, white products with high yields.

The influence of the amount of potassium hydroxide on the structure of cyclotetrasiloxanolate- $\left(\mathrm{CH}_{2}\right)_{3} \mathrm{SH}$ was analyzed. Contrary to the synthesis with the ratio [silane] $/[\mathrm{KOH}]=1$, the product obtained with [silane]/ $[\mathrm{KOH}]=2$ did not precipitate from the reaction mixture. After $24 \mathrm{~h}$ at room temperature the solution separated into two phases of different color and viscosity. The product was isolated as an orange powder only after the volatiles were removed from the more viscous phase under reduced pressure. It does not have a crystalline structure. Furthermore, products obtained in the reaction with potassium hydroxide, $[\mathrm{KOH}] /[$ silane $]=2$, contained significantly more crystallization water than other products.

${ }^{29} \mathrm{Si}$ CP MAS NMR analysis (Fig. 1) displayed only one peak, at $-60.4 \mathrm{ppm}$, for the potassium cyclosiloxanolate obtained with method 1 (Table $1 /$ entry 2 ). The presence of one peak represents formation of only the all-cis isomer. In other cases the presence of two peaks: a minor one near

Table 1 Summary of reaction conditions and elemental composition of the obtained products

\begin{tabular}{|c|c|c|c|c|c|c|c|c|c|c|c|c|c|}
\hline \multirow{3}{*}{ No } & \multirow{3}{*}{ Mt } & \multirow{3}{*}{ Method } & \multirow{3}{*}{$\begin{array}{l}{[\mathrm{MtOH}]} \\
/[\text { silane }]\end{array}$} & \multirow{3}{*}{$\begin{array}{l}\text { [silane] } \\
/\left[\mathrm{H}_{2} \mathrm{O}\right]\end{array}$} & \multicolumn{8}{|c|}{ Elemental Analysis } & \multirow{3}{*}{$\mathrm{Y}[\%]$} \\
\hline & & & & & \multicolumn{3}{|c|}{ Found } & \multirow{2}{*}{ nEtOH } & \multirow{2}{*}{$\mathrm{nH}_{2} \mathrm{O}$} & \multicolumn{3}{|c|}{ Calculated } & \\
\hline & & & & & $\% \mathrm{C}$ & $\% \mathrm{H}$ & $\% \mathrm{~S}$ & & & $\% \mathrm{C}$ & $\% \mathrm{H}$ & $\% \mathrm{~S}$ & \\
\hline 1 & $\mathrm{KOH}$ & 1 & 1 & 1 & 21.2 & 3.9 & 16.1 & 1 & 5 & 20.2 & 5.3 & 15.4 & 71 \\
\hline 2 & $\mathrm{KOH}$ & 1 & 1 & 1 & 20.0 & 4.6 & - & - & 2 & 19.7 & 4.4 & 17.5 & 39 \\
\hline 3 & $\mathrm{KOH}$ & 1 & 1 & 1 & 19.2 & 4.8 & 16.1 & - & 5 & 18.3 & 4.9 & 16.3 & 90 \\
\hline 4 & $\mathrm{KOH}$ & 1 & 1 & 1 & 20.3 & 5.3 & 14.8 & 1 & 5 & 20.2 & 5.3 & 15.4 & 72 \\
\hline 5 & $\mathrm{NaOH}$ & 1 & 1 & 1 & 22.3 & 4.6 & 14.4 & - & 1 & 22.1 & 4.7 & 19.7 & 102 \\
\hline 6 & $\mathrm{KOH}$ & 1 & 2 & 1 & 12.7 & 3.3 & 11.3 & - & 15 & 12.9 & 4.9 & 11.5 & 102 \\
\hline 7 & $\mathrm{KOH}$ & 2 & 1 & 10 & 21.5 & 5.6 & 12.0 & 1 & 4 & 20.6 & 5.2 & 15.7 & 89 \\
\hline 8 & $\mathrm{KOH}$ & 2 & 1 & 10 & 22.1 & 5.1 & 15.8 & 2 & 1 & 23.8 & 5.2 & 15.9 & 113 \\
\hline 9 & $\mathrm{KOH}$ & 2 & 1 & 10 & 22.4 & 6.2 & 12.1 & 2 & 3 & 22.8 & 5.5 & 15.2 & 66 \\
\hline
\end{tabular}

Calculated values correspond to the composition of products according to the results of elemental analysis $\mathrm{nEtOH}, \mathrm{nH}_{2} \mathrm{O}$ - number of ethanol and water molecules in the product 
Fig. $1{ }^{29}$ Si CP MAS NMR spectrum of the product obtained by method $1,[\mathrm{KOH}] /[$ silane $]=1$ (Table $1 /$ entry 2 )

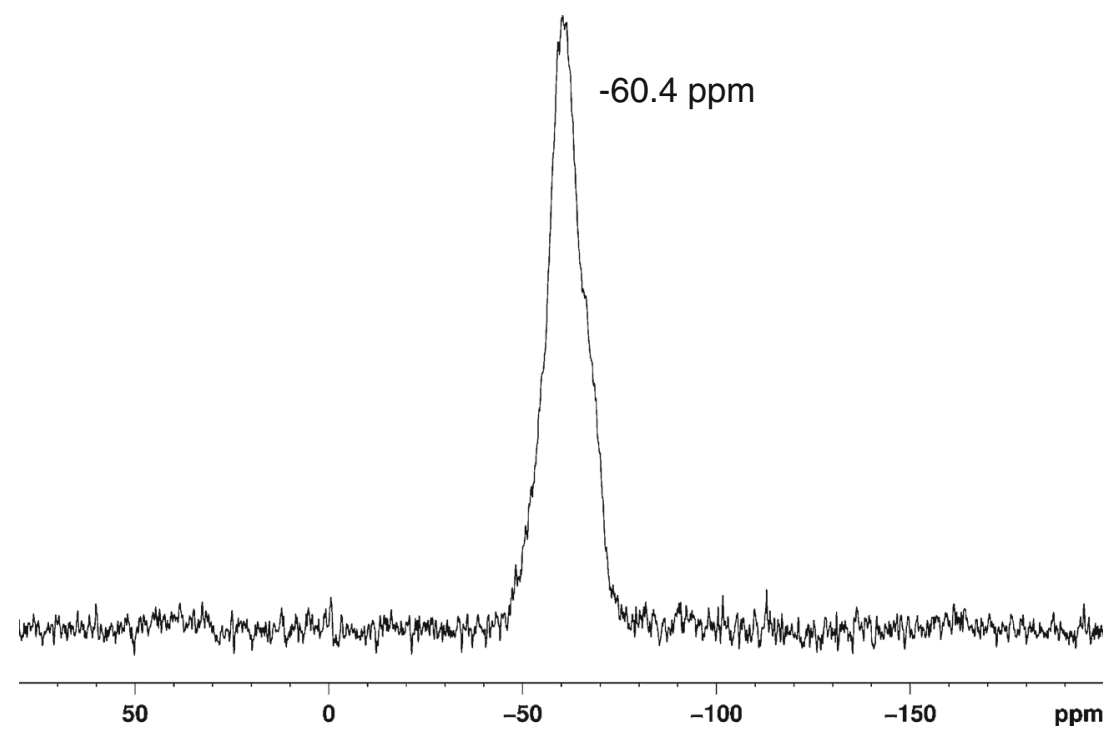

-60 ppm and a much bigger one near -70 ppm was noted. The first one is characteristic for cyclic siloxane structures containing $\mathrm{T}^{2}$ units [38]. The peak near $-70 \mathrm{ppm}$ can be assigned to the formation of oligomeric species containing $\mathrm{T}^{3}$ units. It is known that cyclic siloxanes can be distinguished from their linear analogues by the differences in shifts in ${ }^{29} \mathrm{Si}$ NMR analysis [38, 39]. Signals of silicon atoms in cyclic compounds are always present in the lower magnetic field than those characteristic for oligomeric structures. According to differences in the intensity of signals of products obtained by method $1:[\mathrm{NaOH}] /[$ silane $]=1$ (Table 1/ entry 5) (Figure SI 1), [KOH]/[silane]=2 (Table 1/ entry 6) (Figure SI 3), and by method 2 (Table 1/ entry 7) (Figure SI 5) one can conclude that only the first method and the reaction with an equimolar amount of potassium hydroxide $([\mathrm{KOH}] /[$ silane $]=1)$ leads to the formation of the desired cyclotetrasiloxanolate as the main product.

All of the obtained materials were also analyzed by solid state ${ }^{13} \mathrm{C}$ CP MAS NMR. While the analysis of 3-mercaptopropyltrimethoxysilane displayed characteristic resonances at: $9.4 \mathrm{ppm}\left(\mathrm{SiCH}_{2}\right), 28.5 \mathrm{ppm}\left(\mathrm{CH}_{2}\right)$ and 49.8 ppm $\left(\mathrm{CH}_{2} \mathrm{SH}\right)$, the spectrum (Fig. 2) of the product obtained with method 1 (Table $1 /$ entry 2 ) showed peaks characteristic for the 3-mercaptopropyl group: $12.6 \mathrm{ppm}\left(\mathrm{SiCH}_{2}\right), 27.6$ ppm $\left(\mathrm{CH}_{2}\right), 48.2 \mathrm{ppm}\left(\mathrm{CH}_{2} \mathrm{SH}\right)$, and an additional peak at $64.7 \mathrm{ppm}$. The latter one can be assigned as a resonance of the $\mathrm{CH}_{2}$ group bonded to a SK moiety. A similar down-field shift of appropriate ${ }^{13} \mathrm{C}$ resonances with respect to free ligands was observed for $\mathrm{Hg}$ (II) thiolates [40]. The spectra of sodium cyclosiloxanolate (Table $1 /$ entry 5) (Figure SI 2) as well as products obtained by the second method of synthesis (Table 1/ entry 7) (Figure SI 6) displayed peaks of similar shifts, those corresponding to the 3-mercaptopropyl group and a peak near $64 \mathrm{ppm}$. The analogous situation was observed for the product obtained in the reaction with
$[\mathrm{KOH}] /[$ silane $]=2$ (Table $1 /$ entry 6) (Figure SI 4). The presence of the additional peak as well as that characteristic for $\mathrm{CH}_{2} \mathrm{SH}$ can be explained by interactions between potassium silanolates and acidic thiol groups (Scheme 2). Formation of four-centered structures that can lead to equilibrium between potassium silanolates and thiolates was postulated.

Most of the obtained products did not contain ethanol molecules in their structures or the number of alcohol moieties was low. We have not thus observed intense resonances typical for EtOH (19 ppm and $58 \mathrm{ppm}$ ) in their ${ }^{13} \mathrm{C} \mathrm{CP} \mathrm{MAS}$ NMR spectra.

Wide angle X-Ray scattering analysis (Fig. 3) that was carried out for potassium cyclotetrasiloxanolate obtained by method 1 (Table $1 /$ entry 2) seems to confirm the proposed possible interactions between molecules of siloxanolates (Scheme 2). No literature data on WAXS analysis are available for cyclosiloxanolates that could be directly compared to our results. All data that could be found refer to cyclosilanols [34] or trimethylsilyl derivatives of cyclotetrasiloxanolates [30, 34]. X-Ray diffraction patterns of these compounds exhibit typically a set of two diffraction peaks, near $2 \Theta 8-12^{\circ}(d=7-12 \AA)$ and near $2 \Theta 15-18^{\circ}(d=5-6 \AA)$. We have assigned the recorded diffraction peaks to distances in the postulated structure of 3-mercaptopropylsilanolates (Scheme 2). The structure was constructed on the HyperChem platform [41]. The atomic point charges were calculated using the semi-empirical AM1 method and geometry was optimized by the molecular mechanics method (using $\mathrm{MM}+$ force field parameter set with Polak-Ribiere energy minimization algorithms).

All of the obtained cyclotetrasiloxanolates contained solvate molecules of water and/or alcohol (Table 1). The products obtained by the second synthetic method contained more molecules of ethanol in their structure than 
Fig. $2{ }^{13} \mathrm{C}$ CP MAS NMR

analysis of the product obtained by method 1 , [silane $] /[\mathrm{KOH}]=1$ (Table $1 /$ entry 2)
$27.6 \mathrm{ppm}$

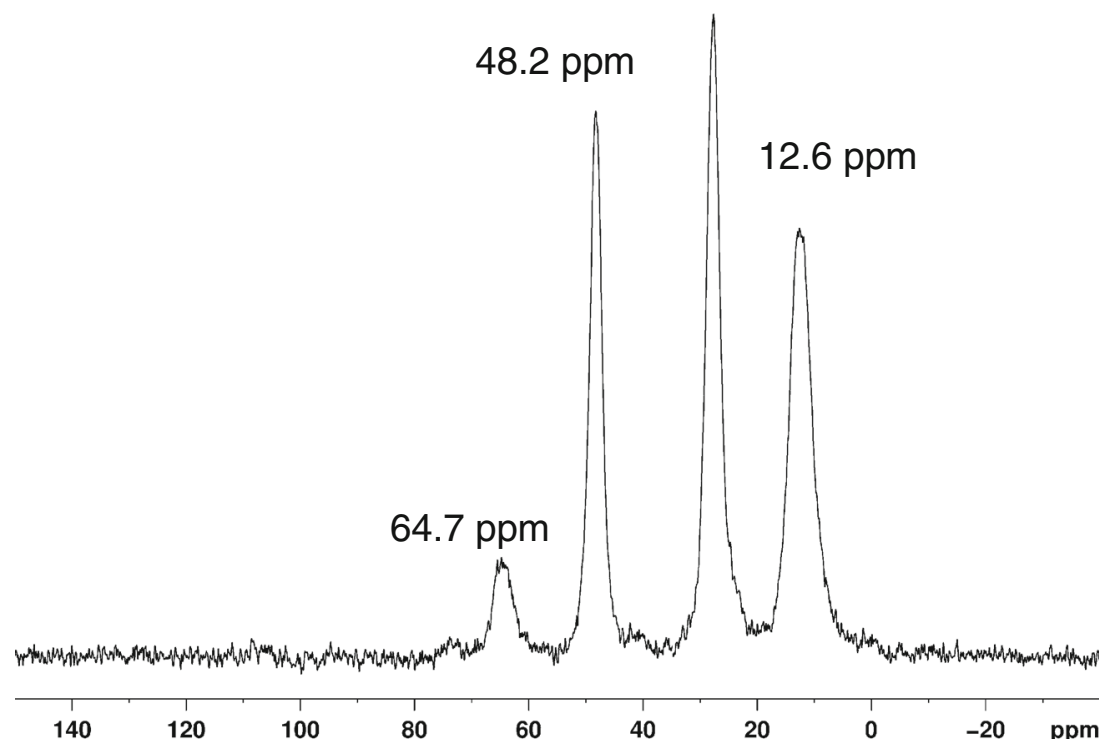

products obtained by the first method. The applied alkali metal hydroxide also influenced the kind of ligand molecules present in the final product. According to elemental analysis, potassium cyclotetrasiloxanolates $([\mathrm{KOH}] /[$ silane $]=1)$ contain both water and ethanol moieties, but the corresponding sodium cyclotetrasiloxanolates

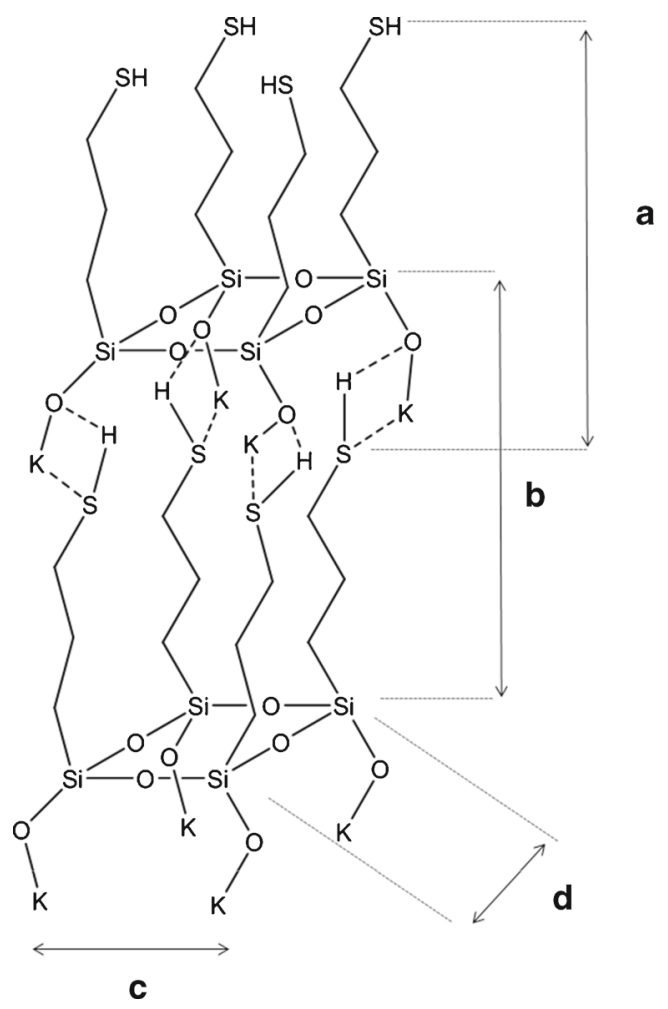

Scheme 2 Postulated interactions between molecules of potassium cyclotetrasiloxanolates have on average only one water molecule in their structure.

FTIR spectra (Fig. 4) recorded for the product synthesized by method 1 , in the reaction with an equimolar amount of potassium hydroxide, displayed all bands characteristic for mercaptopropyl groups: $660-700 \mathrm{~cm}^{-1}\left(\nu \mathrm{CH}_{2}\right)$, 1380-1400 cm $\mathrm{cm}^{-1}\left(\nu \mathrm{CH}_{2}\right), 2550 \mathrm{~cm}^{-1}(\nu \mathrm{SH}), 2940 \mathrm{~cm}^{-1}$ ( $\left.\mathrm{CH}_{2} \mathrm{SH}\right)$ [42-45] and bands near: $1000 \mathrm{~cm}^{-1}, 1100 \mathrm{~cm}^{-1}$, $1250 \mathrm{~cm}^{-1}$ characteristic for $\mathrm{Si}-\mathrm{CH}_{2}-\mathrm{R}$ stretching [42-45]. Peaks near $1000-1130 \mathrm{~cm}^{-1}$ and near $600-700 \mathrm{~cm}^{-1}$ are also characteristic for $\mathrm{Si}-\mathrm{O}-\mathrm{Si}$ asymmetric stretching vibrations [42-45]. The band near $800-900 \mathrm{~cm}^{-1}$ can be assigned as stretching vibrations in cyclic siloxane compounds as well as O-Si-O ${ }^{-}$anionic groups [42, 46, 47]. IR spectra of all products displayed the above mentioned vibration bands but only products obtained in the reactions with potassium hydroxide showed a band near $1600-1700 \mathrm{~cm}^{-1}$. It corresponds to $\delta(\mathrm{H}-\mathrm{O}-\mathrm{H})$ and $\delta(\mathrm{O}-\mathrm{H})$ vibrations and indicates the presence of interstitial water in the samples [48, 49]. The absence of this band in the spectra of the product obtained in the reaction with sodium hydroxide can be explained by a very low amount of water in its structure. On the other hand, the product of reaction with two-fold excess of $\mathrm{KOH}$ has a large amount of physically bound $\mathrm{H}_{2} \mathrm{O}$. It is reflected by the presence of a broad band near $3000 \mathrm{~cm}^{-1}$ in its FTIR spectrum.

Thermogravimetric analysis of products obtained by method 1 in the reaction with potassium (Table 1/ entry 2) (Figure 5) and sodium hydroxide (Table 1/ entry 5) showed two temperature ranges (Figure SI 7) in which the products underwent thermal changes: at $90^{\circ} \mathrm{C}$ and between $200-400^{\circ} \mathrm{C}$. The first peak can be assigned to the removal of water from the crystal structure. The other one corresponds to thermal decomposition of mercaptopropyl groups 
Fig. 3 X-Ray diffractogram of the product obtained by method 1 with potassium hydroxide (Table $1 /$ entry 2 )

Fig. 4 Comparison of solid state IR analysis for all obtained products: a Method 1, $[\mathrm{KOH}] /[$ silane $]=2($ Table 1/entry 6); b Method 1, $[\mathrm{KOH}] /[$ silane $]=1$ (Table $1 /$ entry 2); c Method 1, reaction with $\mathrm{NaOH} ; \mathbf{d}$ Method 2

Fig. 5 TGA analysis for product obtained by method 1 $[\mathrm{KOH}] /[$ silane $]=1$ (Table 1/entry 2)
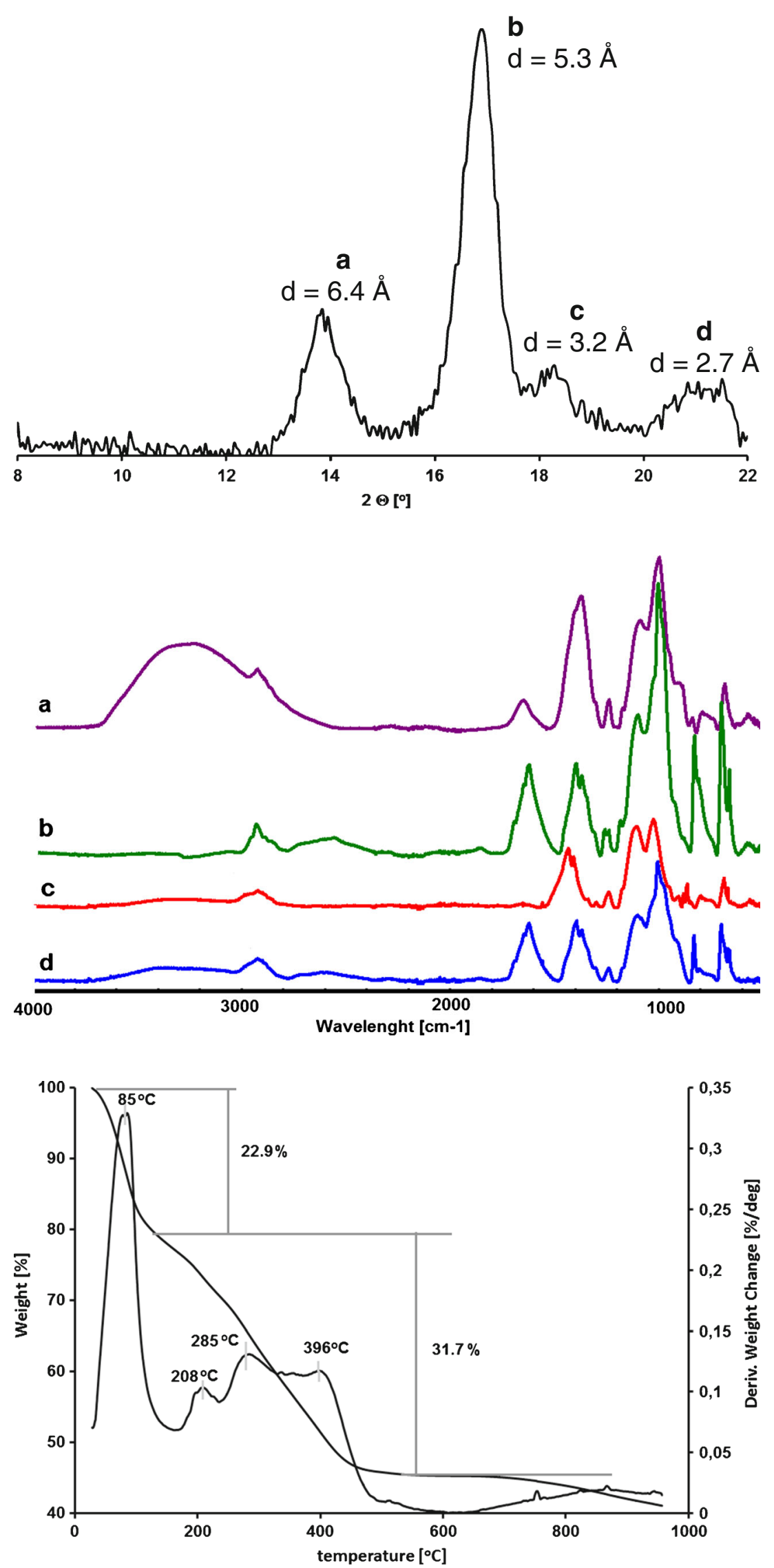
Fig. 6 DSC analysis of the product obtained by method 1 $[\mathrm{KOH}] /[$ silane $]=1$ (Table $1 /$ entry 4$)$, second heating

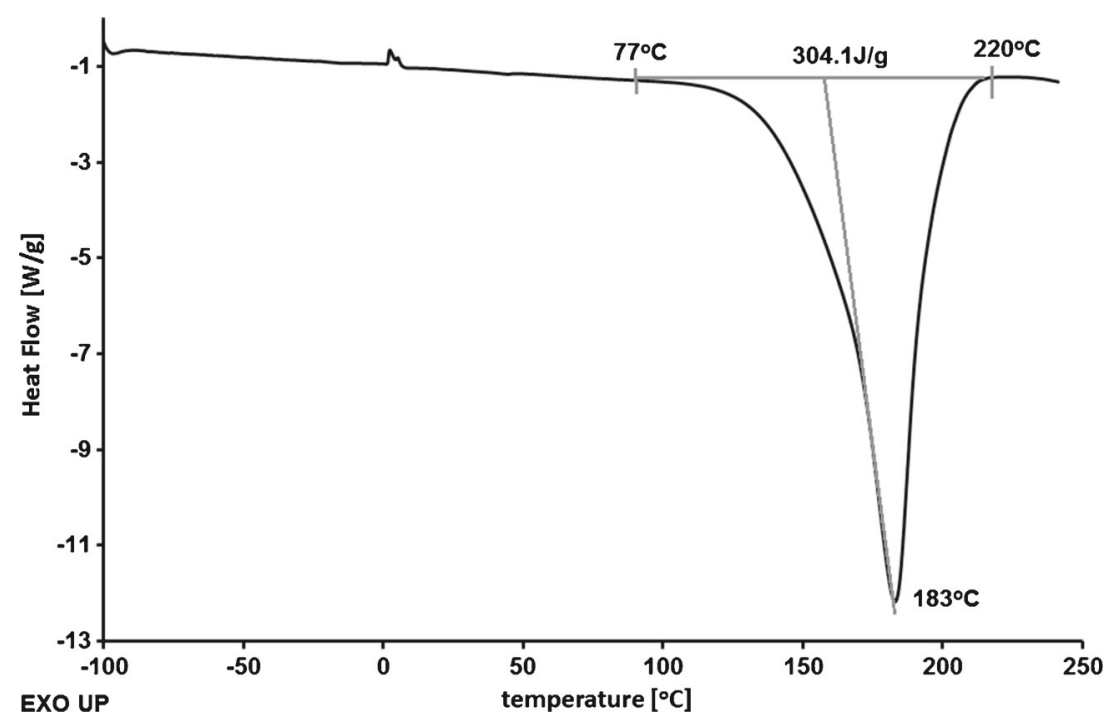

and takes place in three steps. According to bond dissociation enthalpies these three steps correspond to dissociation of S-C $(\Delta \mathrm{H}=713 \mathrm{~kJ} / \mathrm{mol}), \mathrm{C}-\mathrm{C}(\Delta \mathrm{H}=618 \mathrm{~kJ} / \mathrm{mol})$ and $\mathrm{C}-\mathrm{Si}$ $(\Delta \mathrm{H}=447 \mathrm{~kJ} / \mathrm{mol}$ ) bonds [50]. Decomposition of the product obtained in the reaction with $[\mathrm{KOH}] /[$ silane $]=2$ (Table 1/entry6) proceeds in three steps (Figure SI 8). Apart from the peak near $360^{\circ} \mathrm{C}$, there are two other peaks: at $60^{\circ} \mathrm{C}$ and $95^{\circ} \mathrm{C}$. These peaks can be associated with removal of different types of water: physically bound through hydrogen bonds and that present in the crystal structure.

DSC analysis of all products obtained by method 1 displayed small peaks near $0-10^{\circ} \mathrm{C}$ that can be assigned to melting of free water molecules and a large, endothermic transition at $183^{\circ} \mathrm{C}([\mathrm{KOH}] /[$ silane $]=1$ - Table 1/entry4) (Fig. 6) that can be assigned as melting of cyclosiloxanolates. In comparison to other products (Figures SI 9 and SI 10), the endothermic peak of the cyclosiloxanolate obtained by method 1 is sharp and relatively narrow.

\section{Conclusions}

Cyclotetrasiloxanolates bearing 3-mercaptopropyl groups at silicon atoms have been synthesized for the first time with good yield. Their structure has been studied by ${ }^{29} \mathrm{Si}$ and ${ }^{13} \mathrm{C}$ CP MAS NMR spectroscopy, Wide-Angle X-ray Scattering and vibrational spectroscopy. We have found that under appropriate reaction conditions only the all-cis isomer of potassium 2,4,6,8-tetra(3-mercaptopropyl) cyclotetrasiloxanolate or branched oligomeric species can be obtained. Interestingly, it was found that potassium silanolate moieties and thiol groups can interact with each other in the solid (crystalline) state. Formation of four-centered thiosilanolate structures has been postulated.
Acknowledgments This work was supported by the Centre of Molecular and Macromolecular Studies, Polish Academy of Sciences grant 551-30.

\section{References}

1. Dong F, Ha C-S (2012) Macromol Res 20:335-343

2. Brown JF, Vogt LH, Katchman A, Eustance JW, Kiser IM, Krantz IW (1960) J Am Chem Soc 82:6192-6195

3. Zhou Q, Yan S, Han CC, Xie P, Zhang R (2008) Adv Mater 20:2970-2976

4. Tang H, Sun J, Jiang J, Zhou X, Hu T, Xie P, Zhang R (2002) J Am Chem Soc 124:10482-10488

5. Li Z, Cao X, Xu H, Xie P, Cao M, Zhang R (1999) React Funct Polym 39:1-7

6. Liu C, Liu Y, Shen Z, Xie P, Zhang R, Yang J, Bai F (2001) Macromol Chem Phys 202:1581-1585

7. Ren Z, Cao X, Xie P, Zhang R, Yan S, Ma Y (2009) Chem Commun 46:4079-4081

8. Lee EC, Kimura Y (1997) Polym J 29:678-684

9. Gao Q, Qi S, Wu Z, Wu D (2011) Thin Solid Films 519:64996507

10. Zhang ZX, Hao JK, Xie P, Zhang XJ, Han CC, Zhang RB (2008) Chem Mater 20:1322-1330

11. Choi S-S, Lee AS, Lee HS, Back K-Y, Choi DH, Hwang SS (2011) Macromol Res 19:261-265

12. Choi S-S, Lee AS, Lee HS, Jeon HY, Baek K-Y, Choi DH, Hwang SS (2011) J Polym Sci Part A Polym Chem 49:5012-5018

13. Kowalewska A, Nowacka M Patent Application WIPO ST 101C PL399575

14. Kawakami Y, Kakihana Y, Miyazato A, Tateyama S, Hoque MA (2011) Adv Polym Sci 235:185-228

15. Abe Y, Suyama K, Gunji T (2006) Chem Lett 35:114-115

16. Suyama KI, Gunji T, Arimitsu K, Abe Y (2006) Organometallics 25:5587-5593

17. Unno M, Suto A, Matsumoto H (2002) J Am Chem Soc 124:1574-1575

18. Unno M, Kawaguchi Y, Kishimoto Y, Matsumoto H (2005) J Am Chem Soc 127:2256-2263

19. Lee WS, Choi S-S, Hwang SS, Baek K-Y, Hong SH, Lee EC, Lee J-C (2012) Eur Polym J 48:1073-1081 
20. Hirotsu M, Taruno S, Yoshimura T, Ueno K, Unno M, Matsumoto H (2005) Chem Lett 34:1542-1543

21. Bilyachenko AN, Korlyukov AA, Levitskii MM, Antipin MY, Zavin BG (2007) Russ Chem Bull Int Ed 56:543-545

22. Murugavel R, Voigt A, Walawalkar MG, Roesky HW (1996) Chem Rev 96:2205-2236

23. Levitsky MM, Zavin BG, Bilyachenko AN (2007) Russ Chem Rev 76:847-866

24. Mortalo C, Caneschi A, Eliano D, Faranda S, Marvaud V, Pizzotti M, Shchegolikhina O, Zucchi C, Palyi G (2007) J Cluster Sci 18:217-236

25. Pashchenko V, Zang M, Wolf B, Zhelitsyna L, Auner N, Shchegolikhina, O, Pozdniakova Y, Schuetz F, Kopietz P, Kolar M (2007) CR Chemie 10:89-95

26. Molodtsova YA, Pozdnyakova YA, Blagodatskikh IV, Shchegolikhina, O I (2003) Russ Chem Bull Int Ed 52:2722-2731

27. Dubchak IL, Shklover VE, Levitskii MM, Zhdanov AA, Struchkov YT (1980) Zh Strukt Khim 21:103-110. [J Struct Chem USSR]

28. Pozdniakova YA, Lyssenko KA, Korlyukov AA, Blagodatskikh IV, Auner N, Katsoulis D, Shchegolikhina OI (2004) Eur J Inorg Chem:1253-1261

29. Shchegolikhina OI, Pozdniakova YA, Antipin MY, Katsoulis D, Auner N, Herrschaft B (2000) Organometallics 19:1077-1082

30. Pozdnyakova YA, Chetverikov AA, Lyssenko KA, Peregudov AS, Buzin MI, Shchegolikhina OI, Matukhina EV (2007) Russ Chem Bull 56:77-82

31. Bilyachenko AN, Dronova MS, Yalymov AI, Korlyukov AA, Shul'pina LS, Arkhipov DE, Shubina ES, Levitsky MM, Kirilin AD, Shul'pin GB (2013) Eur J Inorg Chem:5240-5246

32. Pozdniakova YA, Lyssenko KA, Korlyukov AA, Zhelitsyna L, Auner N, Shchegolikhina O (2013) J Organomet Chem 729:8694
33. Ito R, Kakihana Y, Kawakami Y (2009) Chem Lett 38:364-365

34. Ronchi M, Pizzotti M, Biroli AO, Macchi P, Lucenti E, Zucchi C (2007) J Organomet Chem 692:1788-1798

35. Unno M, Takada K, Matsumoto H (1998) Chem Lett 27:489-493

36. Unno M, Kawaguchi Y, Kishimoto Y, Matsumoto H (2005) J Am Chem Soc 127:2256-2264

37. Shchegolikhina OI, Pozdnyakova YA, Chetverikov AA, Peregudov, A S, Buzin MI, Matukhina EV (2007) Russ Chem Bull 56:83-90

38. Abe Y, Gunji T (2004) Prog Polym Sci 29:149-182

39. Wijnen PWJG, Beeten TPM, de Haan JW, Rummens CPJ, van de Ven LJM, Santen RA (1989) J Non-Cryst Solids 109:85-94

40. Rabbani G, Al-Arfaj AR, Ahmed S, Saleem M, Hameed A, Akbar E (2009) Spectroscopy 23:45-50

41. HyperChem (TM) Professional 7.51, Hypercube, Inc., 1115 NW 4th Street, Gainesville, Florida 32601, USA

42. Chalmers JM, Griffiths PR (2002) Handbook of vibrational spectroscopy. John Wiley, Chichester

43. Colthup NB, Daly LH, Wiberley SE (1964) Introduction of infrared and Raman spectroscopy. Academic press, New York

44. Socrates G (1994) Infrared characteristic group frequencies. John Wiley, New York

45. Stuart BH (2004) Infrared spectroscopy: fundamentals and applications. John Wiley, Chichester

46. Farmer VC (1974) The infrared spectra of minerals. Mineralogical Society, London

47. Lazariev AH (1968) Kolebatielnyje spektry i strojenie silikatow, Leningrad

48. Phung KP, Le VH, Nguyen VM (2011) Adv Nat Sci: Nanosci Nanotechnol 2:045014

49. Ng CW, Ding J, Gan LM (2001) J Solid State Chem 156:400-407

50. Luo Y-R (2003) Handbook of bond dissociation energies in organic compounds. CRC Press LLC, Boca Raton 